Stefano Dugheri ${ }^{1}$

Alessandro Bonari ${ }^{2}$

Ilenia Pompilio ${ }^{2}$

Pierpaolo Boccalon ${ }^{1}$

Daniela Tognoni ${ }^{3}$

Michele Cecchi ${ }^{3}$

Massimo Ughi ${ }^{4}$

Nicola Mucci ${ }^{2}$

Giulio Arcangeli ${ }^{2}$

\title{
ANALYTICAL STRATEGIES \\ FOR ASSESSING OCCUPATIONAL EXPOSURE TO ANTINEOPLASTIC DRUGS IN HEALTHCARE WORKPLACES
}

\author{
Careggi University Hospital, Florence, Italy \\ ${ }^{1}$ Occupational Medicine Division, Laboratory of Industrial Hygene and Toxicology \\ ${ }^{2}$ Department of Clinical and Experimental Medicine \\ ${ }^{3}$ Pharmacy AD Preparation Unit \\ ${ }^{4}$ Health and Safety Service
}

\begin{abstract}
Background: Cytotoxic antineoplastic drugs (ADs), widely used in treating cancer, are considered hazardous in the workplace and thus require safe handling practices. An analytical protocol for environmental and biological AD monitoring in the healthcare environment has been developed, since Europe lacks clear guidelines and regulations for cytostatic preparation and handling. Material and Methods: Liquid chromatography-tandem mass spectrometry (LC-MS/MS) was used for measuring contemporaneously 20 multi-class cytostatic compounds and urinary $\alpha$-fluoro- $\beta$-alanine, whereas platinum was detected by inductively coupled plasma mass spectrometry (ICP-MS). Sampling procedures and analytical conditions were optimized and the assays were validated. Environmental AD monitoring data, collected in 2009-2017, for a total of 3749 wipe tests and 57720 determinations, was evaluated. Results: The proportion of positive samples gradually decreased from $11.7 \%$ in 2010 to $1 \%$ in 2017 , however, 2266 determinations were positive. No urine sample had detectable concentrations of any of the 4 drugs considered (0/398 samples). Conclusions: These improvements are so large that the key role played by the new, more stringent rules for preparing and administering $\mathrm{ADs}$ is evident. Hence, the analytical method involving multi-element determinations allows for a more thorough and complete investigation into the AD contamination of work environments. Med Pr 2018;69(6):589-604
\end{abstract}

Key words: occupational exposure, LC-MS/MS, ICP-MS, urine, antineoplastic drugs, wipe test

Corresponding author: Stefano Dugheri, Careggi University Hospital, Occupational Medicine Division, Laboratory of Industrial Hygene and Toxicology, Largo Piero Palagi 1, 50139 Florence, Italy, e-mail: stefano.dugheri@unifi.it Received: December 18, 2017, accepted: June 14, 2018

\section{INTRODUCTION}

Worldwide, more than 11 million new cases of cancer are diagnosed each year, and that number is expected to rise to 16 million by 2020 [1]. The global cancer drug market has been valued at approx. USD 112.90 billion in 2015 and is expected to generate revenue of around USD 161.30 billion by the end of 2021, with an estimated compound annual growth rate of 7.4\% between 2016 and 2021. The blood cancer segment dominates the market in terms of revenue [2]. The cancer drug market is partitioned based on the different therapeutic segments, including chemotherapy, immunotherapy, targeted therapy, hormone therapy and others. Chemotherapy is expected to continue to be the highest revenue-generating sector through 2020 (about 50\%) [3]. Today, out of the 331 oncology wards surveyed in Italy, about $80 \%$ are served by centralized preparation units; on average, each unit has a volume of activity of around 20000 doses per year, although some units administer over 40000 [4].

The toxic effects of antineoplastic chemotherapy drugs used for cancer treatment have been well known since their introduction in the 1940s. However, beyond the patient safety concerns arising from the necessary use of these drugs for treatment, the occupational risks 
to healthcare workers handling these drugs during their duties still need to be fully assessed. Addressing the toxicity of these drugs has been an ongoing challenge for clinicians and, more recently, for the occupational health community. Reproductive and fetal-development effects like those observed in patients have been reported in healthcare workers exposed to cytotoxic agents at considerably lower doses than those administered to patients [5]. A meta-analysis of 14 studies, performed in 1966-2004 in the United States and Europe, described an association between exposure to antineoplastic drugs and adverse reproductive effects on female healthcare workers [6]. Positive results of cytogenetic studies in chromosomal aberrations analysis (peripheral lymphocytes), sister chromatid exchanges observations, micronucleus tests, comet assay and gene mutations assay were described at medical personnel, especially among nurses exposed to different cytostatics $[7,8]$.

In 2004, the National Institute for Occupational Safety and Health (NIOSH) published an alert on antineoplastic and other hazardous drugs that proposed safe handling practices for all healthcare workers. That list was recently updated in 2016 to include drugs newly approved by the U.S. Food and Drug Administration (FDA) [9]; slightly more than a half of these hazardous drugs are classified as antineoplastic/cytotoxic agents. Despite the NIOSH guidelines, studies continue to document ongoing exposure to antineoplastic drugs (ADs), in part because compliance has been voluntary and irregular, and in part since contamination is not being regularly monitored at the ward level [10-16].

Although other safe handling guidelines have been produced by professional organizations in the last few years, including the American Society of Health-System Pharmacists and the Oncology Nursing Society, no Europe-wide legislation, guidelines or minimum standards exist to specifically govern AD administration processes. To fill this gap, in 2017, the first European consensus paper on risk management for health personnel handling injectable antineoplastic drugs, is carried out under the patronage of the Italian Society of Hospital Pharmacists and of the Italian Association of Oncology Nurses [4].

The basic occupational health approach to minimizing exposure to any workplace hazard uses a combination of industrial hygiene control methods that are applied in a specific order or hierarchy. Specifically, environmental and biological monitoring are useful tools for catching contamination trends, identifying corrective measures, and increasing workers' awareness.
Today, no occupational exposure limits exist for ADs in any work environments, although a few authors have proposed thresholds for single drugs and many occupational exposure bands are indicated from manufacturers, assigning cytostatics into categories on the basis of potency and health outcomes associated in particular with inhalation road exposure [17]. Only one organization, the United States Pharmacopeia, e.g., has indicated a maximum threshold for cyclophosphamide (CP), although Sessink et al. [18] proposed CP reference values for a traffic-light color-coding model, to easily show the level of CP environmental contamination and urine excretion. Kiffmeyer et al. [19], instead, produced a substance-independent guideline based on the 90th percentile values of the 8 chemotherapy drugs found in the highest concentrations in a large-scale German study. Stricter threshold guidance values for platinum $(\mathrm{Pt})$ and 5 -fluorouracil (5-FU), such as the 50th or 75th percentile, were suggested by a German research group $[10,20]$. In addition, Hedmer et al. [21] reported hygienic guidance values (HGVs) for CP and ifosfamide (IP) in different categories of surfaces for hospital workplaces. Recently, Sottani et al. [22] have suggested HGVs for 4 ADs based on the 90th percentile of wipe-sampling data distributions.

While the research on surface and biological monitoring for ADs has continued with enthusiasm, demonstrated by the number of recent publications reporting improved technology for wipe [23-25] and urine [26-28] sampling, only a limited number of the studies published consider both matrices $[11,13,29]$.

In this work a new monitoring protocol for multiclasses of antineoplastic drugs in wipe tests and in 4 biological exposure compounds has been thoroughly evaluated contextualizing and standardizing them according to the time needed for sample preparation and analysis. In addition to laboratory testing, this paper also describes the validation protocol used to assess cytotoxic drug monitoring in 2009-2017 in Careggi University Hospital in Florence.

\section{MATERIAL AND METHODS}

To evaluate the contamination of work areas, environmental and biological AD monitoring surveys were carried out in 2009-2017 in Careggi University Hospital in the cytostatic preparation and administration units. Careggi University Hospital is a campus with many different buildings, which together house over $5800 \mathrm{em}$ ployees. Careggi is one of Europe's largest polyclinics 
with 1650 beds, 54000 in-patients, 22000 day-hospital admissions, and nearly 10 million medical examinations per year. This public hospital, located on the northern edge of Florence, is integrated with the University of Florence. During this study, the centralized AD preparation unit - inside the Pharmacy Department had a volume of activity that went from 15793 administrations in 2009 to 48086 in 2017. Consequently, to deal with this higher volume, in 2012 the preparation and administration unit introduced ChemoClave closedsystem drug transfer devices (ICU Medical Inc., USA) and the CareFusion set for multivia infusion (Becton Dickinson, USA). Additional equipment, such as the Diana Hazardous Drug Compounding System (ICU Medical Inc., USA), a needle-free, user-controlled automated compounding system for the safe reconstitution and preparation of hazardous drugs, has been used from 2014 on. The centralized AD preparation unit, protected by an anteroom, is equipped with 4 IIA2-class biological safety cabinets, and is ventilated with $70 \%$ recirculated air and 30\% fresh air. In addition to the preparation site, in 16 main patient administration facilities, surfaces/objects that come into contact with ADs are touched and handled by the healthcare staff. General working procedures, technical and personal protective equipment as well as safety precautions are, however, standardized.

The levels of CP, 5-FU, IP, dacarbazine (DC), gemcitabine (GEM), methotrexate (MT), mitomicyn C (MITC), irinotecan (IRT), vincristine (VNC), vinblastine (VNB), epirubicin (EPI), doxorubicin (DXR), etoposide (ETP), docetaxel (DTX), paclitaxel (PTX), topotecan (TPT), melphalan (MP), idarubicine (IDC), fotemustine (FTM), citarabine (CTB), and Pt - as a marker of cis-, carbo-, and oxali-platin - were all measured in wipe samples, as well as CP, IP, $\mathrm{Pt}$, and $\alpha$-fluoro- $\beta$-alanine (FBAL) in urine samples.

\section{Wipe sampling and analytical procedures}

Wipe samples were collected from the preparation and administration units at the beginning (B-WS) and at the end of the work shift (E-WS); when possible, samples were also collected in the middle of the shift. Wipe sampling was performed using a standardized kit (Figure 1), which comprises all the necessary tools: $5 \times 5 \mathrm{~cm}$, 3-layer nonwoven fabric (Cat. No. 26015Y, 6-layer Luxor-Net, STS Medical Group Luigi Salvadori, Italy) wetted with $500 \mu \mathrm{l}$ of an equimolar water/methanol solution stored in 5-ml (Cat. No. 309649, Becton Dickinson, USA) or 2.5-ml (Cat. No. CH002LL, Chirana
T. Injecta, Slovakia) disposable syringes with a male Luer-Lok connection fitting, tweezers with a joint for disposable pipette tips, and a precise instruction manual with photos and a video on the correct technique for obtaining wipe samples. The 5-ml syringes, used for manual desorption until 2016, were preassembled with Combi Caps (Cat. No. 39.000.00.223, P. J. Dahlhausen \& Co. GmbH, Koln, Germany), while the $2.5-\mathrm{ml}$ syringes were configured using $0.2 \mu \mathrm{m}$ GHP Acrodisc 13-mm filters (Cat. No. PN4567, Pall Corporation, USA), and the new adaptors developed by Chromline (Italy) that make the system more robust and ready for automated desorption. The latter, automated desorption system was adopted starting from 2016

Selected surfaces were wiped in the 3 standard directions (down, left, and right) over an area of $20 \times 20 \mathrm{~cm}$; tweezers held the wipe during sampling. However, for smaller surfaces, for which this size was not feasible, the exact sampled area was recorded. The same procedure was performed for the internal and external faces of the healthcare workers' polychloroprene glove, between one change and another (every $30 \mathrm{~min}$ ). The wipe was immediately placed inside a syringe for desorption.

Desorption of the ADs from the wipe, wetted with $2 \mathrm{ml}$ of equimolar water/methanol solution containing $20 \mathrm{ng} / \mathrm{ml}$ of internal standards (ISs), was then performed, being filtered in-line using the $0.2 \mu \mathrm{m}$ filters in a 2 -ml vial, either manually or in automated mode. In the latter case, the procedure was done off-line using a Flex GC autosampler

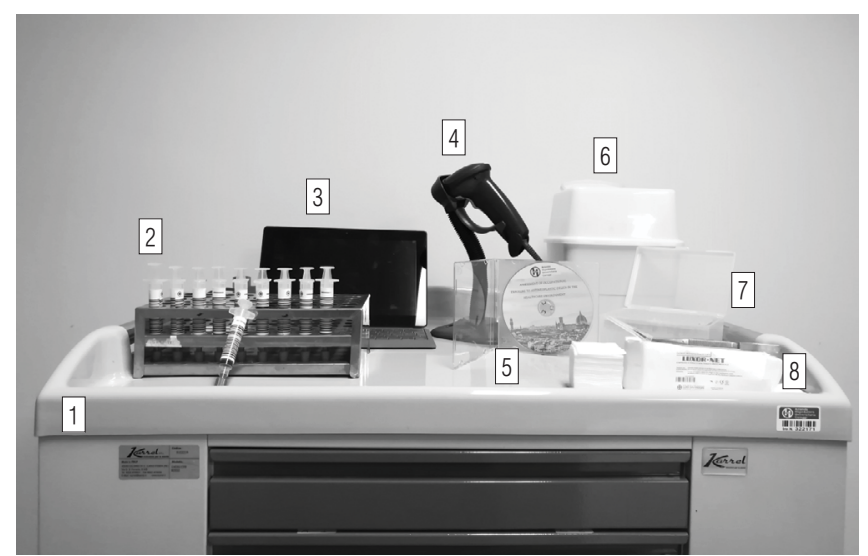

1 - wheel-trolley, 2 - 5-ml syringes, used for manual desorption, preassembled with $5 \times 5 \mathrm{~cm} 3$-layer nonwoven fabric and Combi Caps, 3 - personal computer, 4 - barcode reader, 5 - CD instruction manual with photos and a video on the correct technique for obtaining wipe samples, 6 - pipette tips waste container, 7 - pipette tips, $8-5 \times 5 \mathrm{~cm} 3$-layer nonwoven fabric and tweezers with joint for disposable pipette tips.

Figure 1. Wipe sampling kit 
(EST Analytical, USA) equipped with one 98-position tray for 2-ml vials and two 45-position trays for 2.5$\mathrm{ml}$ syringes. The $2.5-\mathrm{ml}$ syringes were transported one by one between the 45 -position tray and the vial for desorption.

For the $20 \mathrm{ADs}$, quantitative analyses were performed via a liquid chromatography (LC) triple quadrupole mass spectrometry (MS) detector (LC-MS/MS, Alliance e2695/Quattro Micro API, Waters, USA) using fragment ions produced via collision-induced fragmentation. The LC analysis was performed on a YMCPack ODS-AQ $5 \mu \mathrm{m}, 2.1 \times 250 \mathrm{~mm}$ column (Cat. No. AQ12S05-25Q1QT, YMC Co. LTD, Japan) using:

water,

$0.1 \%$ formic acid $/ 60 \%$ acetonitrile $/ 40 \%$ methanol solution for gradient:

- 0 min, $0 \%$,

- $1 \mathrm{~min}, 5 \%$,

- $1.3 \mathrm{~min}, 10 \%$,

- 5-8 min, $10-40 \%$,

- 8-10 min, $40-60 \%$,

- 12-14 min, $60-85 \%$,

- 18-20.4 min, $85-100 \%$,

- $22 \mathrm{~min}, 0 \%$.

The flow rate was $0.3 \mathrm{ml} / \mathrm{min}$, and the column temperature was $25^{\circ} \mathrm{C} ; 5$ microliters of desorbed wipe was injected. Total run time for each sample was $23 \mathrm{~min}$. The MS utilized multiple reaction monitoring (MRM) and positive electrospray ionisation (ESI+) for the following ADs: DC precursor $\mathrm{m} / \mathrm{z} 183.16>$ product $\mathrm{m} / \mathrm{z} 166.15$, GEM 264.26 > 112.06, MT 455.17 > 308.17, MITC 335.19 > 242.13 , IRT $587.35>124.10$, VNC $825.57>765.45$, VNB $406.40>271.87$, EPI $544.28>130.07$, DXR $544.21>$ 397.067, CP $261.19>106.01$, IP $261.20>92.00$, ETP 589.23 > 229.09, DTX $808.48>$ 527.25, PTX $854.54>569.36$, daunorubicin (IS) 528.26 > 321.12, TPT $422.33>377.19$, MP $305.22>288.19$, trophosphamide (IS) $323.21>154.02$, cephalomannine (IS) 832.49 > 264.19, IDC $498.01>290.95$, CTB $244.13>111.98$, FTM $316.11>108.99$. Negative ESI mode, instead, was used for 5-FU (128.96 > 41.79 and 5-chlorouracil [IS] $144.96>41.79$ ) determination.

The Pt quantitative analyses were made using an iCAP Q inductively coupled plasma mass spectrometry (ICP-MS, Thermo Fisher Scientific, USA) with a Cetac ASX520 autosampler (Cetac Technologies, USA), a PFA cyclonic spray chamber, and a $2.5 \mathrm{~mm}$-internal-diameter quartz injector. Platinum levels were measured in standard mode (STD), following 1:20 dilution of wipe extraction solution with $1 \%$ hydrochloric acid, peristaltic pump speed - $40 \mathrm{rpm}$, nebulizer gas flow rate $-0.911 / \mathrm{min}$, radio frequency power $-1.550 \mathrm{~W}$, cool gas flow $-14 \mathrm{l} / \mathrm{min}$, auxiliary gas flow $-0.89 \mathrm{l} / \mathrm{min}$. Dwell times were $50 \mathrm{~ms}$ for ${ }^{195} \mathrm{Pt}$ and ${ }^{194} \mathrm{Pt}, 10 \mathrm{~ms}$ for internal standards, with 40 sweeps per replicate and 3 replicates per sample. Moreover, dwell times for ${ }^{114} \mathrm{In}$ were $1 \mathrm{~s}$, and $0.05 \mathrm{~s}$ for ${ }^{72} \mathrm{Ge}$, with 20 sweeps per replicate and 3 replicates per sample. The instrument was tuned on a daily basis to ensure optimization.

\section{Biological monitoring}

Twenty-four-hour urine samples were collected from 398 healthcare employees - nurses, technicians, and pharmacists - who handled ADs at the same time as when the wipe samples were collected. All urine samples were collected separately in 2-1 polypropylene widemouthed containers before AD preparation/administration and until the next day. The urine volume of each sample was measured, and samples were stored at $-20^{\circ} \mathrm{C}$ until further use. Liquid chromatography-tandem mass spectrometry methods for assessing CP and IP in urine implemented the same instrument settings as indicated above in the section "Wipe sampling and analytical procedures." For sample preparation the procedure proposed by Pretty et al. [29] was applied with modifications. A $5 \mathrm{ml}$ aliquot of urine was transferred into a $6-\mathrm{ml}$ pre-conditioned (with $5 \mathrm{ml}$ methanol) solid-phase extraction cartridge (Cat. No. WAT043395, Sep-Pak Vac, $500 \mathrm{mg}$ C18 cartridges, Waters, USA), rinsed (with $5 \mathrm{ml}$ of deionised water) and eluted with $2 \mathrm{ml}$ of ethyl acetate, which was then dried at $40^{\circ} \mathrm{C}$ until completely evaporated. The sample was then reconstituted in $200 \mu \mathrm{l}$ of the equimolar water/methanol solution.

For FBAL determination, the method proposed by Ndaw et al. [26] was applied with slight modification. Urine sample of $1 \mathrm{ml}$ in quantity was mixed with $50 \mu \mathrm{l}$ of $ß$-alanine-d4 IS solution $(2 \mathrm{mg} / \mathrm{l})$, followed by $500 \mu \mathrm{l}$ of $10 \mathrm{mM}$ sodium borate and then $400 \mu \mathrm{l}$ of a 2,4-dinitrofluorobenzene (DNFB) derivatizing solution (10 g/l in acetonitrile). After being heated at $65^{\circ} \mathrm{C}$ for $30 \mathrm{~min}$, $50 \mu \mathrm{l}$ of $50 \mathrm{mM}$ phosphoric acid was added to the solution, which was then purified via $60 \mathrm{mg}$ Oasis HLB 3-ml cartridges (Cat. No. WAT094226, Waters, USA) as follows; the derivatized sample was transferred into a pre-conditioned $(2 \mathrm{ml}$ methanol plus $2 \mathrm{ml}$ of $15 \mathrm{mM}$ phosphoric acid solution) solid-phase extraction cartridge, followed by rinsing ( $2 \mathrm{ml}$ of $10 / 90$ methanol/15 mM phosphoric acid solution) and elution with $2 \mathrm{ml}$ of acetonitrile, which was then evaporated at $40^{\circ} \mathrm{C}$. The sample was subsequently reconstituted in $1.8 \mathrm{ml}$ of acetonitrile. Quantitative analyses were performed via LC-MS/MS, 
using the same apparatus as above. The mobile phase consisted of:

\section{$25 \mathrm{mM}$ of ammonium formate/water solution, acetonitrile.}

Isocratic elution (5\% of $25 \mathrm{mM}$ of ammonium formate/water solution, $95 \%$ of acetonitrile) was performed on a SeQuant ZIC-HILIC $5 \mu \mathrm{m}, 200 \AA$, $2.1 \times 100 \mathrm{~mm}$ column (Cat. No. 1.50452.0001, Merck KgaA, Germany) set to $50^{\circ} \mathrm{C}$, at a flow rate of $0.4 \mathrm{ml} / \mathrm{min}$. Five microliters was injected. Total run time for each sample was 12 min. The MS was operated in MRM mode and utilized ESI-: IS-derivative $258.08>182.10$, while $272.02>182.16$ and $272.02>252.18$ for the FBAL-derivative. The LC system was coupled with a Three-Column Selector Valve (Waters, USA) for automated switching of the 2 analytical columns between one analysis and the other.

Quantitative analyses for urinary Pt used the same instrument as indicated above in the section "Wipe sampling and analytical procedures," but with different settings. The diluted urine (1:5 with $1 \%$ hydrochloric acid solution), was processed in collision cell (KED) mode, as follows: peristaltic pump speed $-40 \mathrm{rpm}$, nebulizer gas flow rate $-0.91 \mathrm{l} / \mathrm{min}$, radio frequency power $-1.550 \mathrm{~W}$, cool gas flow $-14 \mathrm{l} / \mathrm{min}$, auxiliary gas flow $-0.89 \mathrm{l} / \mathrm{min}$, collision cell gas (helium) flow $-3.5 \mathrm{ml} / \mathrm{min}$.

\section{Validation study}

Blank wipe samples, spiked wipe samples with only the IS solution, and 6 calibration standards prepared by a working solution with 20 ADs were adopted to build up a calibration curve at the following concentrations: $1.25,2.5$, 5, 10, 20, $40 \mathrm{ng} /$ wipe. Five replicates for every standard were analyzed and peak area ratio from each analyte and the internal standards was used to obtain the response factor plot. Therefore least-square linear regression analysis from the response factor plot was applied to estimate slopes and intercepts of the calibration lines, using:

$$
y=m x+b
$$

where:

$y$ - the ratio between the chromatographic area of the analyte and the relative IS,

$\mathrm{m}$ - estimate slopes,

$\mathrm{x}$ - the concentration of the analyte,

b- intercepts.

The limit of detection (LOD) of the assay was calculated according to the formula:
$\mathrm{LOD}=(3 \mathrm{SEb}+\mathrm{b}) / \mathrm{m}$

where:

$\mathrm{SEb}$ - the standard error of the intercept.

The lower limit of quantification (LOQ) was then estimated in the same way using 10SEb, which corresponds to 3.3 LOD. The precision of the assay (as a coefficient of variation - CV\%) was estimated both as within-session and as inter-session repeatability. Within-session accuracy was evaluated by the recoveries (reported as the percentage ratio between the measured and the nominal concentrations) at all concentrations used for the calibration plot. The accuracy values were also compared with the US FDA requirements, for analytical methods validation.

Low $(2 \mathrm{ng} / \mathrm{ml})$, high $(20 \mathrm{ng} / \mathrm{ml})$ level quality control samples (QCs) were prepared and processed in every analytical session from a fresh solution with the ADs with ISs to ensure the precision validity of reported results.

The extraction efficiency and matrix effects for both the processed $\mathrm{ADs}$ and the IS added to the wipe were determined for each cytotoxic drug in 6 replicates. Two recoveries were calculated. The MS matrix's effect, evaluated through the mean relative ionization recovery for the analytes, was calculated as the percentage of decline in response between analytes spiked into the eluate, obtained after extracting the blank wipe, and analytes injected directly into the mobile phase. The recovery from the wipe was calculated as the percentage of decline response, between the wipe spiked with $\mathrm{ADs}$ and the AD spiked solution.

Sampling, analysis, and data management were processed by Stata data analysis and statistical software (StataCorp LLC, USA) and handled by Bika's laboratory information management system (LIMS, Bika Lab System, South Africa) (Figure 2).

\section{RESULTS}

Analytical curves were analyzed and demonstrated to be linear over the concentration range studied, since the correlation coefficients $\left(r^{2}\right)$ were $>0.992$ for all tested compounds. The intra- and inter-day variability for all compounds ranged $1.2-7.2 \%$, hence, the average accuracy and inter-day precision were within the acceptable range. The LOQs for wipe ADs, urinary ADs, and FBAL, respectively were: $0.06-3.61 \mathrm{ng} /$ wipe, $22.9-$ $46.2 \mathrm{ng} / \mathrm{l}, 643 \mathrm{ng} / \mathrm{l}$ (Table 1 and 2). Desorption efficiencies in a syringe from the 3-layer nonwoven fabric 


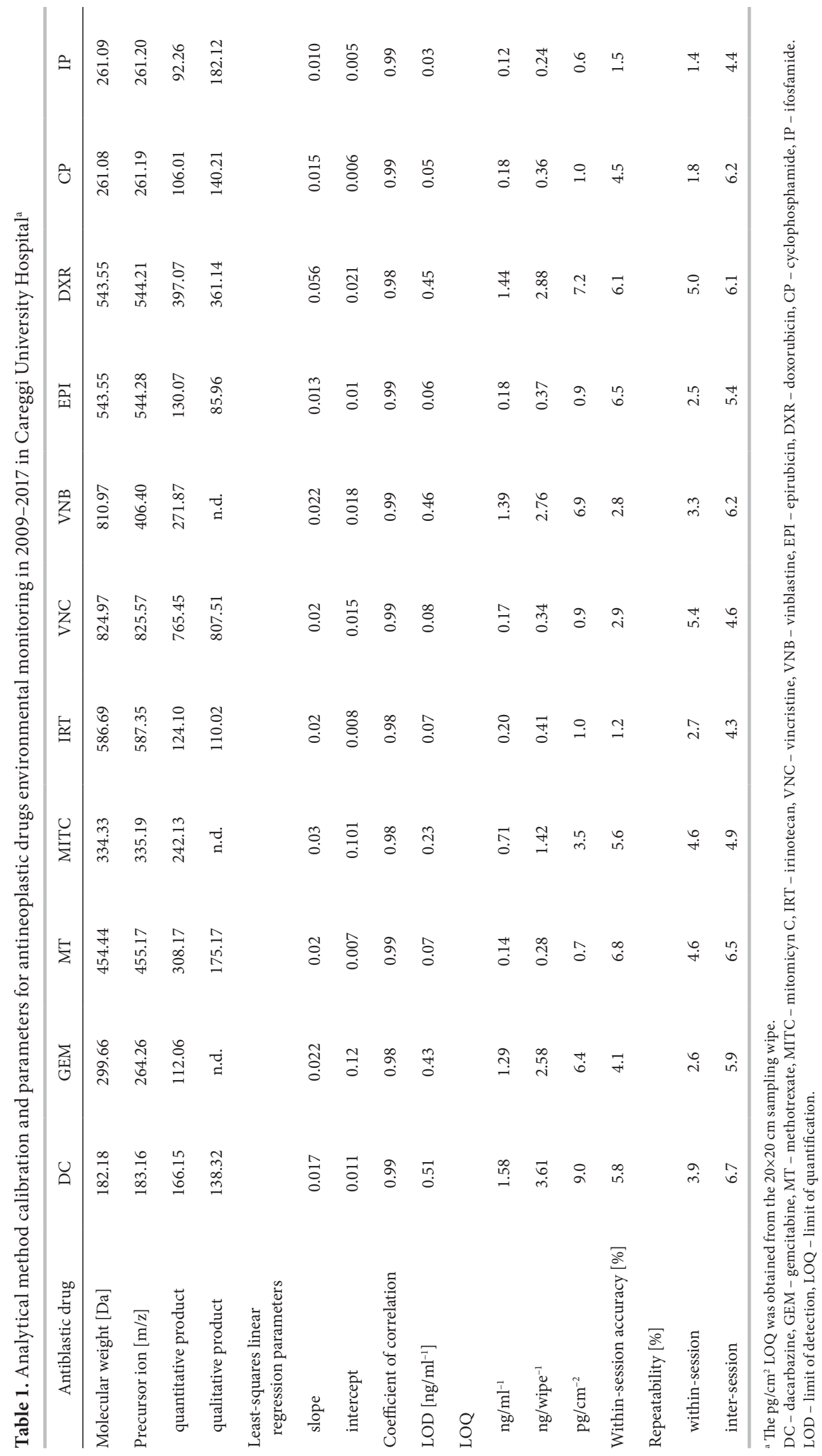




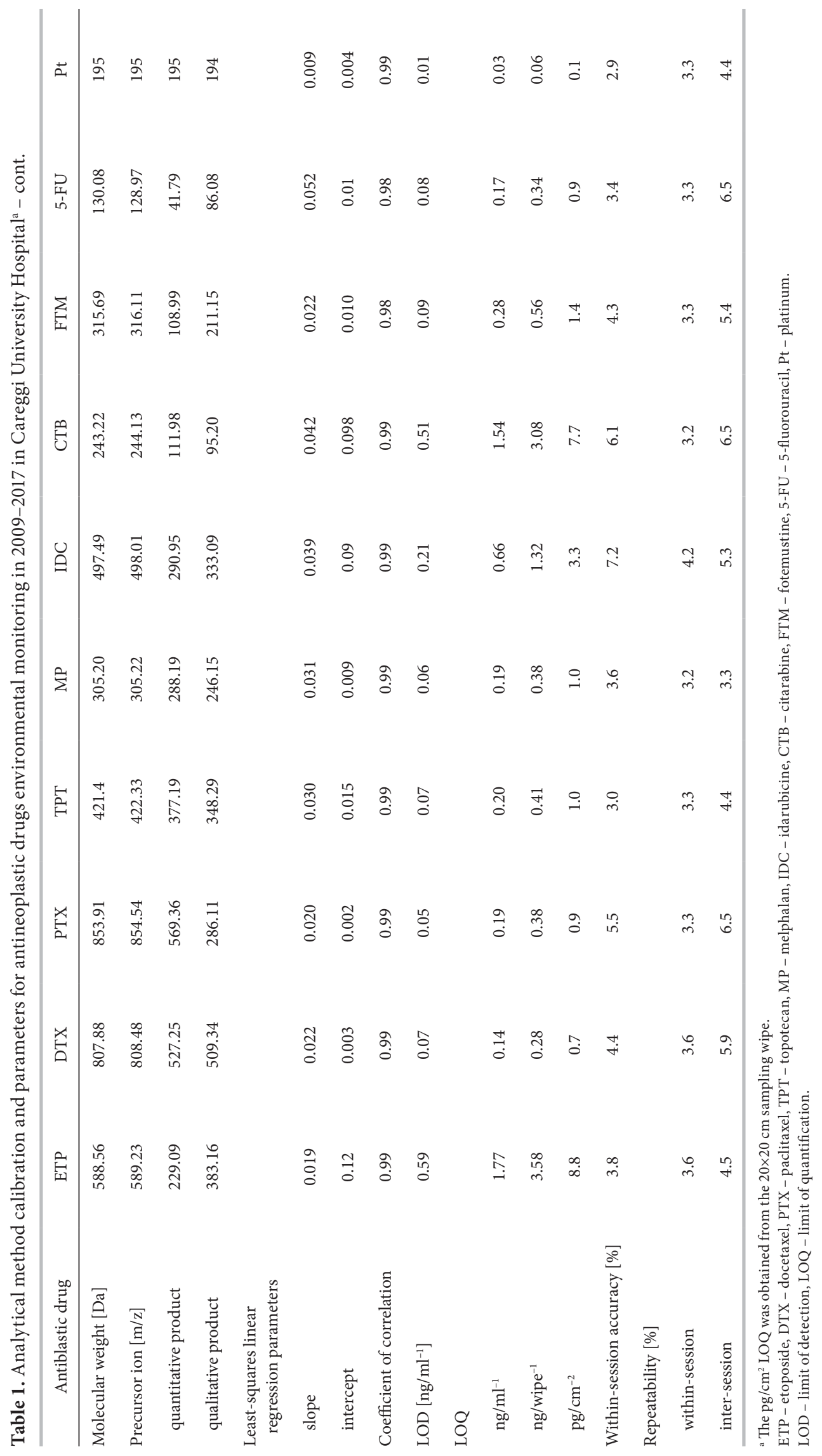




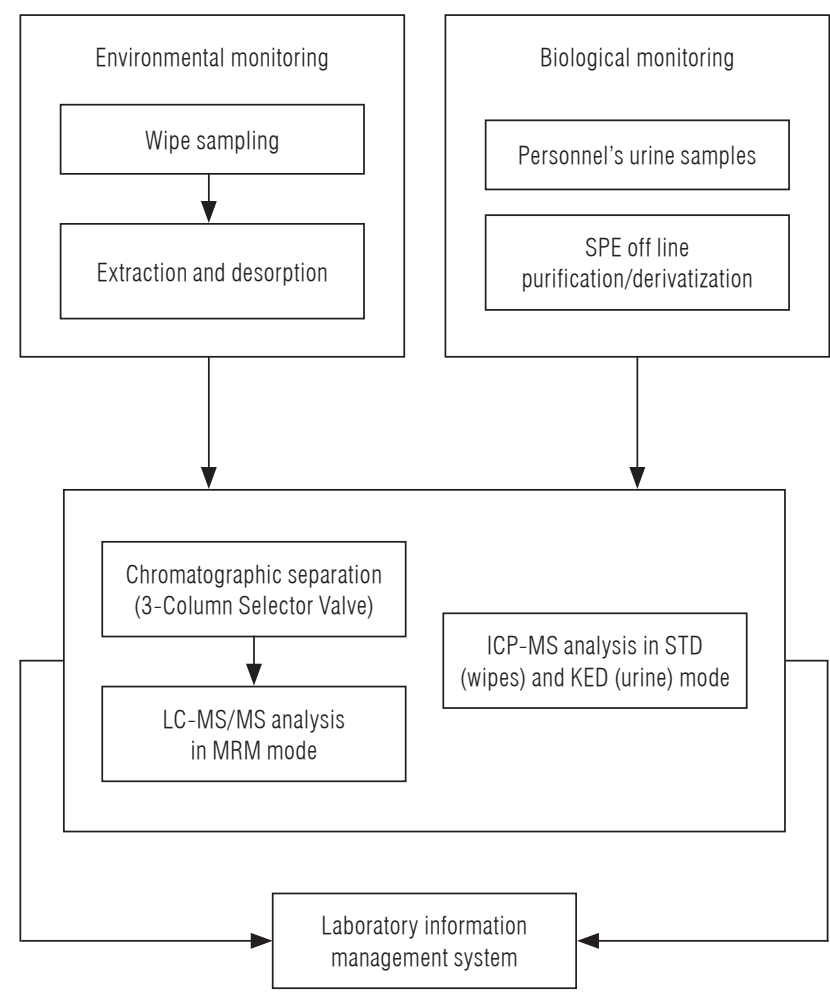

SPE - solid phase extraction, LC-MS/MS - liquid chromatography-tandem mass spectrometry, MRM - multiple reaction monitoring, ICP-MS - inductively coupled plasma mass spectrometry, STD - standard mode, KED - collision cell.

Figure 2. Pretreatment, analysis and data management of biological and environmental ADs monitoring wipes in the $2 \mathrm{ml}$ equimolar water/methanol solution containing $20 \mathrm{ng} / \mathrm{ml}$ of ISs were close to $100 \%$. No significant differences $(\mathrm{p}>0.05)$ were observed between manual and automated desorptions.

In the period considered, a total of 3749 wipe tests were performed and evaluated (Table 3), resulting in $57720 \mathrm{AD}$ determinations (Table 4). Total positive determinations were 2266 (3.9\%), but the proportion of positives progressively declined from a maximum of $11.7 \%$ in 2010 to $1 \%$ in 2017 . Upon scrutiny of the sampling site, the highest concentration of positives was on the floors (24\%), the door handles $(21 \%)$, the work surface of the laminar flow hoods (11\%), and the syringe pumps (10\%). Furthermore, an analysis of the overall data showed (Table 5 and 6 ) that the 6 most frequently-detected substances were CP (18.3\% of all CP determinations), IP (15.2\%), GEM (8.6\%), PTX (4.6\%), IRT (3.7\%), and 5-FU (2.9\%). The 90th percentiles of area contamination levels $\left(\mathrm{pg} / \mathrm{cm}^{2}\right)$ are reported (Table 5) for CP and IP; these limits were adopted by Careggi University Hospital for good hygiene practice. For all other ADs, the analyzed 50th, 75th and 90th percentiles were lower than the LOQs. Antineoplastic drugs positivity at B-WS progressively decreased over the years (from $10.8 \%$ to $0.9 \%$ ). This study's multi-class analysis allowed us to even discern ADs used on some surface 2 days before monitoring (Figure 3). No urine sample had either

Table 2. Analytical method calibration and parameters for antineoplastic drugs biological monitoring in 2009-2017 in Careggi University Hospital

\begin{tabular}{|c|c|c|c|c|}
\hline Variable & $\mathrm{CP}$ & IP & $\mathrm{Pt}$ & FBAL \\
\hline Molecular weight [Da] & 261.08 & 261.09 & 195 & 107.08 \\
\hline Precursor ion $[\mathrm{m} / \mathrm{z}]$ & 261.19 & 261.20 & 195 & 272.02 \\
\hline quantitative product & 106.01 & 92.26 & 195 & 182.16 \\
\hline qualitative product & 140.21 & 182.12 & 194 & 252.18 \\
\hline \multicolumn{5}{|l|}{$\begin{array}{l}\text { Least-squares linear } \\
\text { regression parameters }\end{array}$} \\
\hline slope & 0.30 & 0.57 & 0.21 & 0.07 \\
\hline intercept & 0.34 & 0.94 & 0.32 & 1.60 \\
\hline Coefficient of correlation & 0.99 & 0.99 & 0.99 & 0.99 \\
\hline $\mathrm{LOD}\left[\mathrm{ng} / \mathrm{ml}^{-1}\right]$ & 8.1 & 7.7 & 15.4 & 234 \\
\hline $\mathrm{LOQ}\left[\mathrm{ng} / \mathrm{ml}^{-1}\right]$ & 25.3 & 22.9 & 46.2 & 643 \\
\hline Within-session accuracy [\%] & 7.3 & 4.2 & 4.9 & 4.2 \\
\hline \multicolumn{5}{|l|}{ Repeatability [\%] } \\
\hline within-session & 3.9 & 6.1 & 5.5 & 6.1 \\
\hline inter-session & 5.7 & 5.9 & 5.8 & 5.9 \\
\hline
\end{tabular}

FBAL - $\alpha$-fluoro- $\beta$-alanine.

Other abbreviations as in Table 1. 
Table 3. Positive wipe tests on workplace surfaces in 2009-2017 in Careggi University Hospital: wipes presenting antineoplastic drugs, for samples taken at the beginning and at the end of work shifts

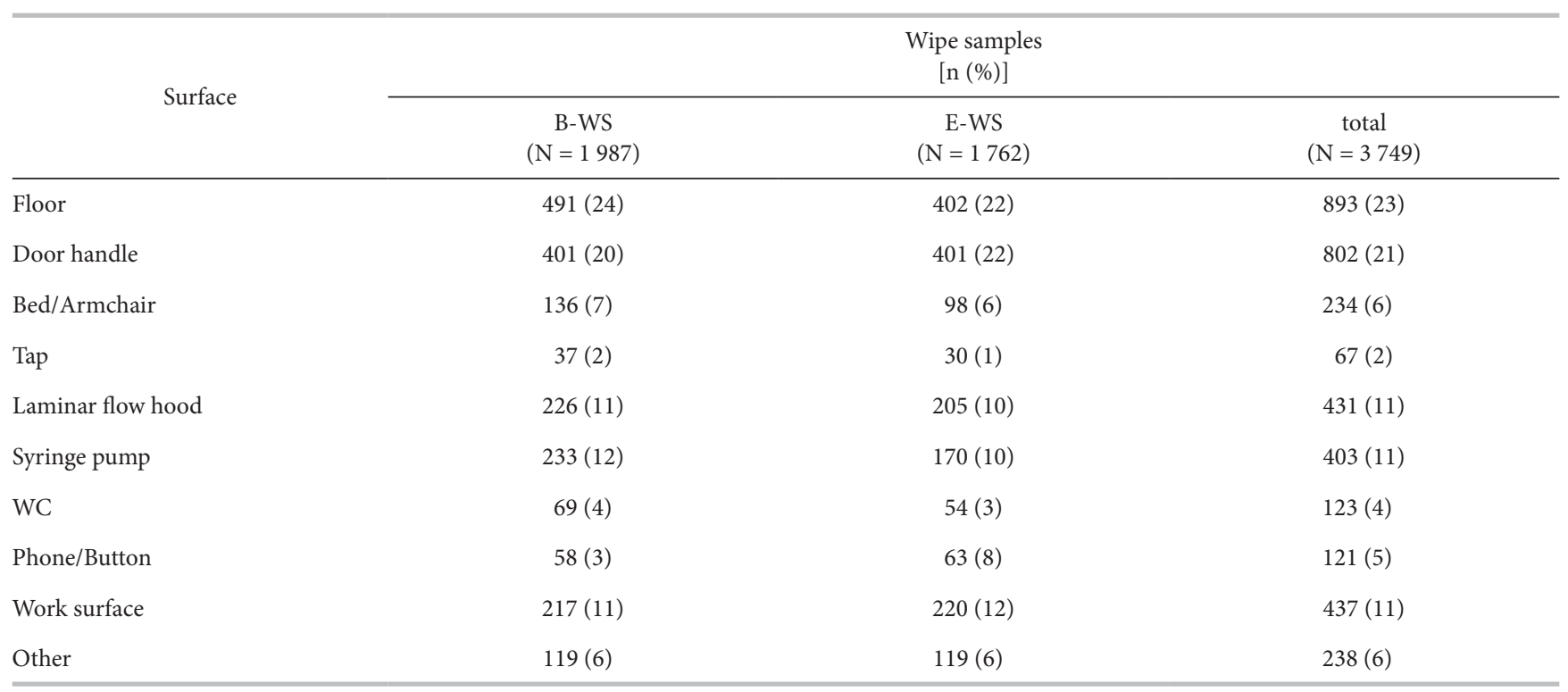

B-WS - beginning of work shifts, E-WS - end of work shifts.

Table 4. Antineoplastic drugs (ADs) determinations in 2009-2017 in Careggi University Hospital: positive results of all ADs on the wipes, on each workplace surface, in sampling at the beginning and at the end of work shifts

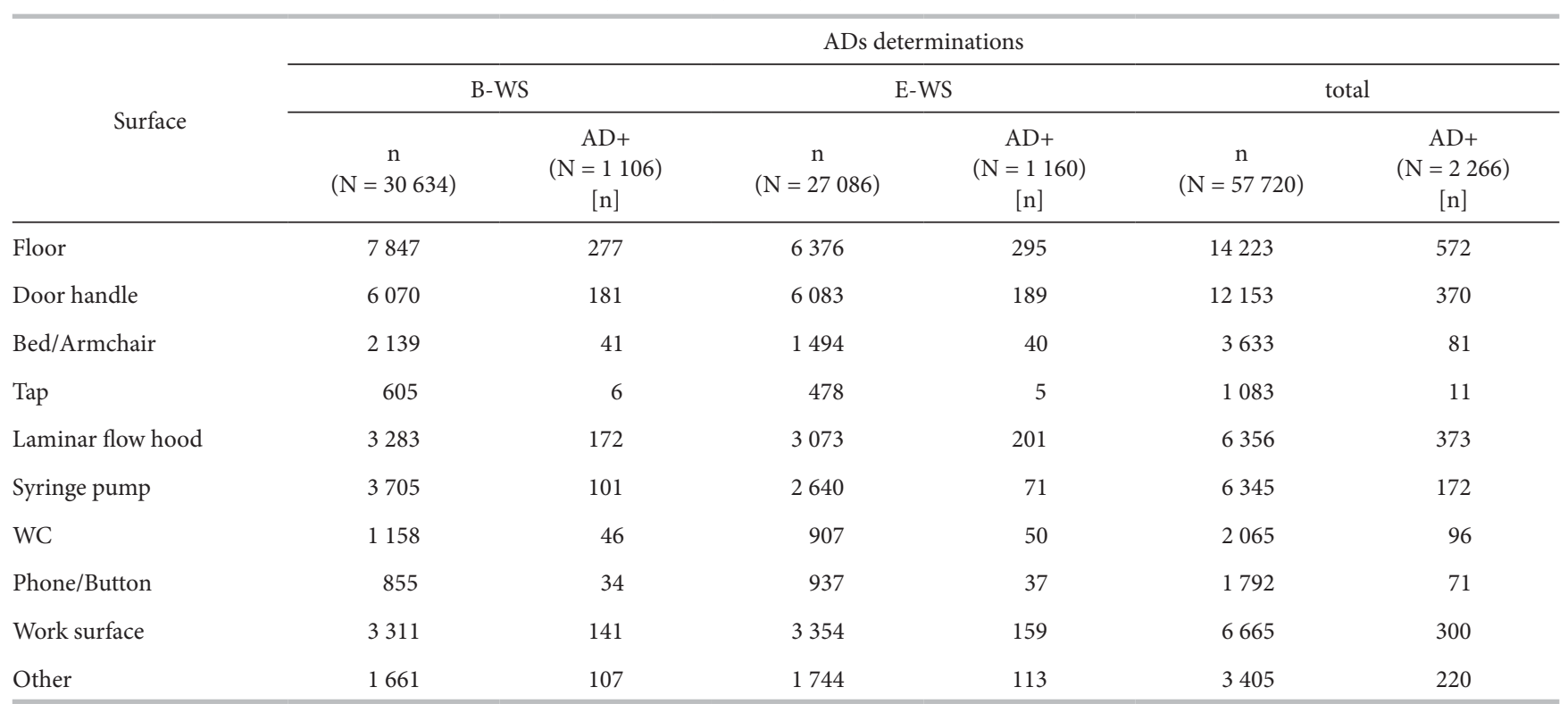

$\mathrm{AD}+-$ positive results of all antineoplastic drugs on the wipes.

Other abbreviations as in Table 3.

detectable or outside-of-the-reference-population concentrations for any of the 4 drugs evaluated (0/398 samples).

\section{DISCUSSION}

High pressure liquid chromatography, which is approaching its 50th anniversary, has always been an im- portant analytical technique in investigating ADs contamination of work environments. The development of new types of columns based on different particle types, sizes, stationary-phase chemistry, and other physical characteristics have played a key role in the expanded usage of LC in discerning these substances. Particularly, the chromatography of 5-FU on surface samples, of 
Table 5. Cyclophosphamide (CP) and ifosfamide (IP) contamination in 2009-2017 in Careggi University Hospital workplaces surveyed at the beginning and at the end of the work shift

\begin{tabular}{|c|c|c|c|}
\hline \multirow{2}{*}{ Substance } & \multicolumn{3}{|c|}{ Work shift } \\
\hline & B-WS & E-WS & total \\
\hline \multicolumn{4}{|l|}{$\mathrm{CP}$} \\
\hline samplings [n] & 1936 & 1713 & 3649 \\
\hline$<\mathrm{LOQ}[\mathrm{n}]$ & 1607 & 1375 & 2982 \\
\hline positives $[\mathrm{n}(\%)]$ & $329(17)$ & $338(19.7)$ & $667(18.3)$ \\
\hline \multicolumn{4}{|c|}{ percentile $\left[\mathrm{pg} / \mathrm{cm}^{2}\right]$} \\
\hline 50 th & $<$ LOQ & $<$ LOQ & $<\mathrm{LOQ}$ \\
\hline 75th & $<$ LOQ & $<\mathrm{LOQ}$ & $<$ LOQ \\
\hline 90th & 45 & 75 & 58 \\
\hline $\max \left[\mathrm{pg} / \mathrm{cm}^{2}\right]$ & 38309 & 44646 & n.d. \\
\hline \multicolumn{4}{|l|}{ IP } \\
\hline samplings [n] & 1962 & 1740 & 3702 \\
\hline$<\operatorname{LOQ}[\mathrm{n}]$ & 1686 & 1452 & 3138 \\
\hline positives $[\mathrm{n}(\%)]$ & $276(14.1)$ & $288(16.6)$ & $564(15.2)$ \\
\hline \multicolumn{4}{|c|}{ percentile $\left[\mathrm{pg} / \mathrm{cm}^{2}\right]$} \\
\hline 50th & $<$ LOQ & $<$ LOQ & $<$ LOQ \\
\hline 75 th & $<$ LOQ & $<$ LOQ & $<\mathrm{LOQ}$ \\
\hline 90th & 32 & 57 & 45 \\
\hline $\max \left[\mathrm{pg} / \mathrm{cm}^{2}\right]$ & 18226 & 214628 & n.d. \\
\hline
\end{tabular}

Abbreviations as in Table 1 and 3. which more than $400 \mathrm{~kg}$ are being administered in Italy each year and $8 \mathrm{t}$ in Germany, has aroused interest in the scientific community. Some authors [23,30,31] proposed LC-MS/MS methods for efficient 5-FU resolution by using Phenomenex Kinetex Biphenyl, Agilent Pursuit XRs Ultra, or Shimadzu SHIM-PACK XRODC C18 columns. Since the goal was to analyze as many ADs as possible in a short time, we selected the YMC-Pack ODS-AQ column, already used by Pretty et al. [29] but only for determination of 5-FU: a hydrophilic C18 material with a balanced surface chemistry leading to elution of moderately basic compounds with no peak tailing and strong retention of polar sample solutes. As a result, we came up with a novel LC-MS/MS method capable of detecting 20 ADs, with simultaneous resolution of the more hydrophilic (5-FU, CTB, DC, GEM) and hydrophobic cytostatics, with excellent sensitivity, thanks to a lower volume of the solvent desorption solution necessary, combined with exhaustive extraction capacity.

In the processes of health risk assessment at work, biological monitoring of occupational exposure often plays a central role in identifying the most suitable risk-control strategies and hygiene conservation programs. Thus, the availability of a validated, highly-sensitive, compound-selective analytical method for measuring a suitable marker of occupational exposure would allow personnel to know the true extent of exposure.

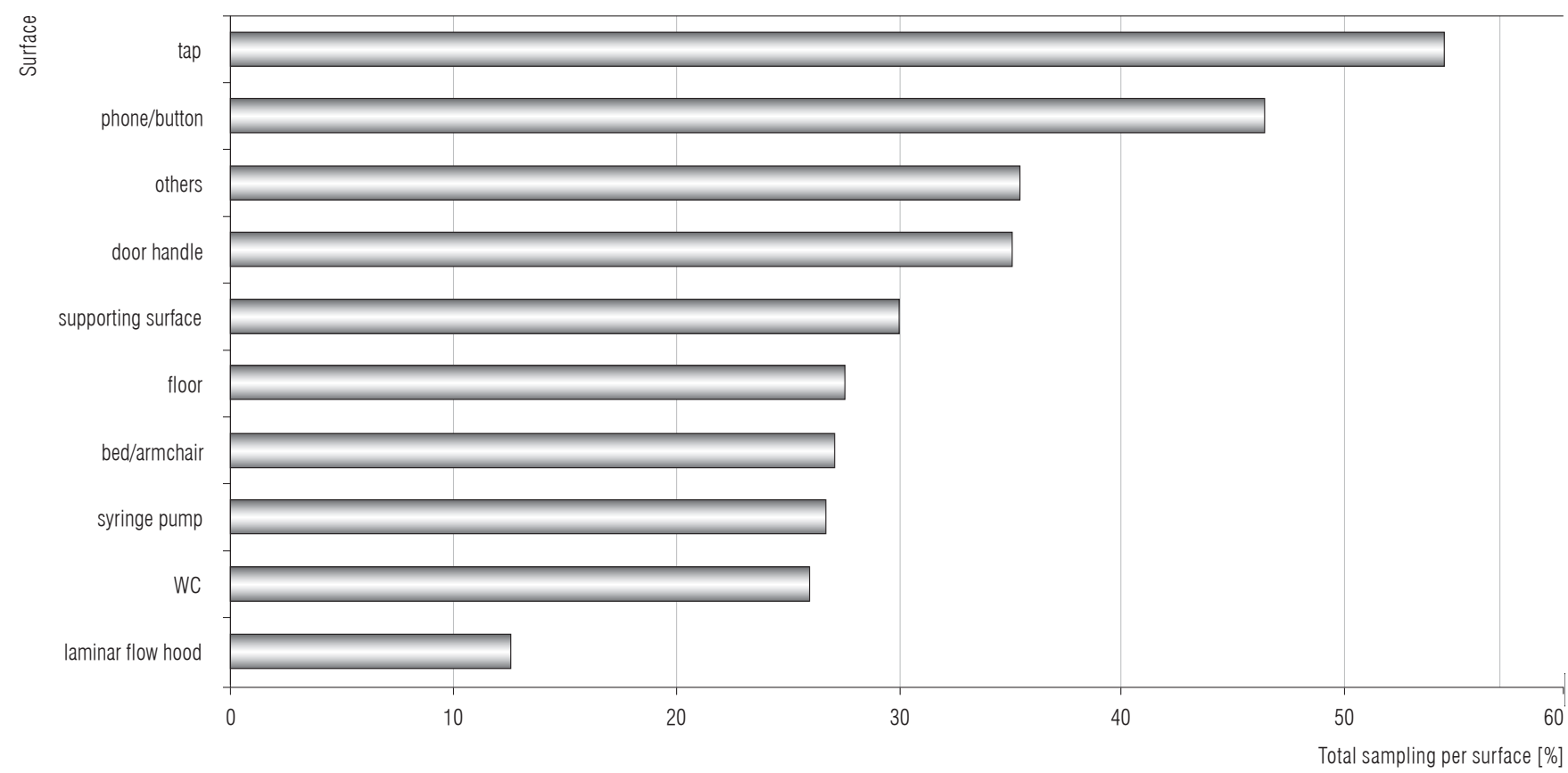

Figure 3. Antineoplastic drug (AD) positive workplace surfaces in monitoring done 2 days after an AD was last used 
Table 6. Positive wipe tests for each antineoplastic drug in Careggi University Hospital workplaces at the beginning and at the end of the work shifts per cytotoxic substance in 2009-2017

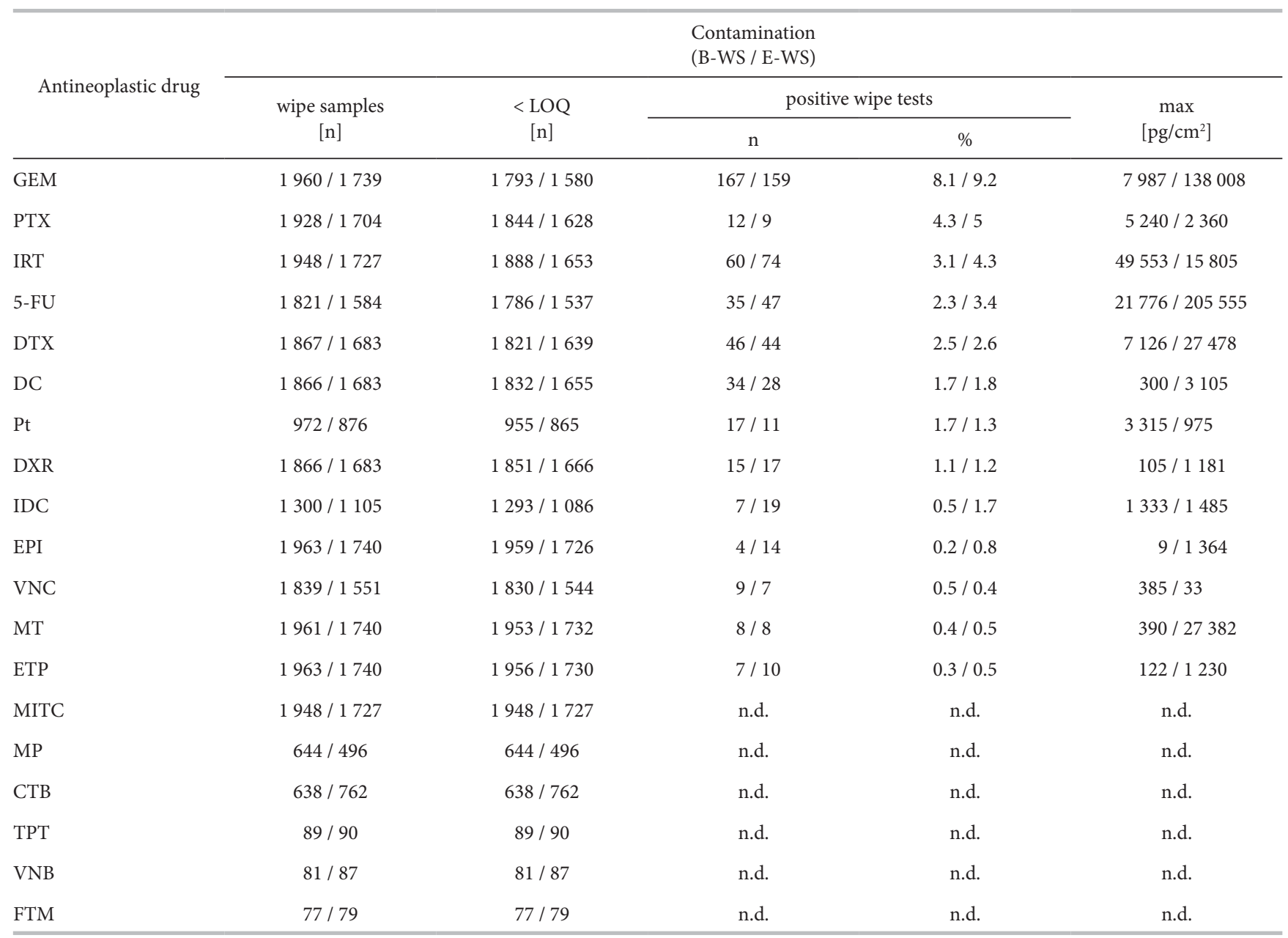

Abbreviations as in Table 1 and 3.

Biological monitoring is particularly important where workplace substances may be absorbed through the skin, where exposure control relies on respiratory protection, or to identify poor work practices. In general, it is assumed that dermal absorption is more likely to occur with drugs with a molecular weight of $<500 \mathrm{Da}$, and less likely for those $>1000 \mathrm{Da}[13]$. Most ADs are relatively small molecules, weighing $<500 \mathrm{Da}$, and, hence, available for dermal uptake from contaminated surfaces. No governmental industrial hygiene association, nevertheless, has ever mentioned biomarkers for professional exposure to cytostatic drugs. Biological monitoring for $\mathrm{CP}$, IP, and $\mathrm{Pt}$ were in line with previous works $[26,32]$ in all those analytical parameters. However, it is important to note that the sensitivity of that method may not be sufficiently adequate for urinary FBAL. The high number of positive biological samples found by Yoshida et al. [11] demonstrates the need to adopt more sensitive analytical techniques; the FBAL determination method proposed by the Japanese research group, a modification of that proposed by Rubino et al. [33], using gas chromatography coupled with high-resolution MS, allowed for a lower order of magnitude of sensitivity than other methodologies. No critical issues with $\mathrm{Pt}$ were noticed by us; Schierl et al. [10] found that nearly all Pt samples were above the detection limit $\left(0.025 \mathrm{pg} / \mathrm{cm}^{2}\right)$.

The significant reduction in surface contamination from ADs found in 2009-2017 in Careggi University Hospital is attributable to:

training and re-training of the staff,

the use of closed systems to prevent any escape of hazardous drugs,

the development of a new cleaning technique for floors and work surfaces.

Going more into detail, the training focused on the following: safety equipment and maintenance, scien- 


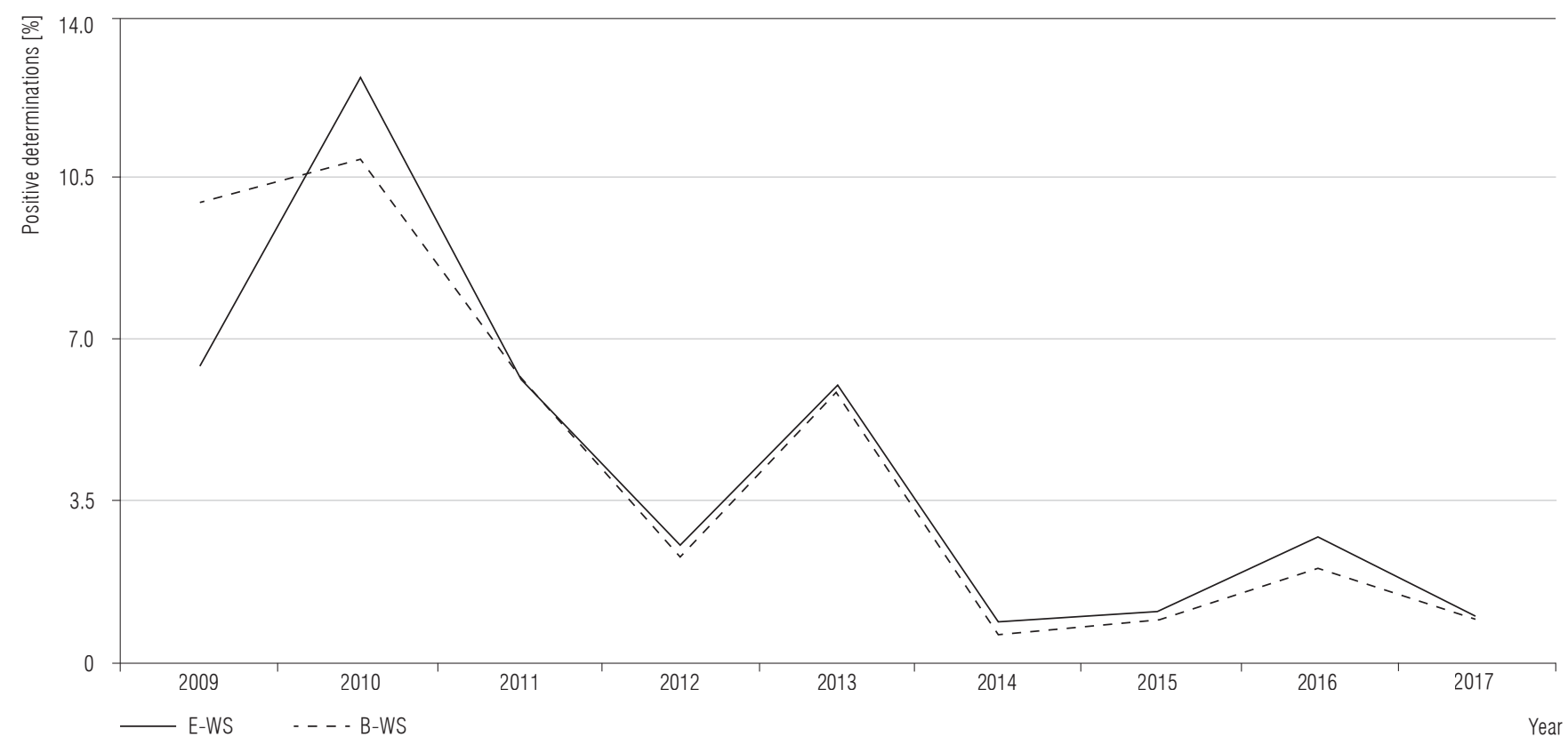

Figure 4. Trend of beginning of work shifts (B-WS) and end of work shifts (E-WS) positive determinations per year in $2009-2017$ at Careggi University Hospital

tific updates, devices for safe handling, personal protective equipment, and emergency care. Secondly, the introduction, in 2012, in Careggi University Hospital of closed-system drug-transfer devices and needleless systems, mandated by US and European regulations, as well as of the Diana System in 2014, contributed to significantly reducing the dispersion of ADs on workplace surfaces. In fact, the high percentage of positivity to $\mathrm{CP}$ and IP, found in the preparation unit in the years 20102013 , is attributable to their format (powder) and to a significant increase in the number of preparations compared to the previous years: $2010(+54 \%), 2011(+24 \%)$, and 2013 (+30\%). Finally, AD concentrations at B-WS progressively decreased over the years thanks to new cleaning products for floors $(0.2 \%$ Marseille soap solution, $0.115 \%$ sodium hypochlorite, and $70 \%$ ethanol, in sequence) and small surfaces, such as the working surface of the laminar flow hoods, syringe pump, phone handset, etc., where Alcavis Bleach-Wipe 1:50 (Angelini Pharma Inc., USA) was used (Figure 4). Furthermore, ADs contamination on the floor, tap, and toilet seat of the workplace bathroom was solved by using disposable WC covers.

\section{CONCLUSIONS}

A new analytical strategy for assessing the healthcare environments used for preparing and administering cy- tostatic compounds in terms of level of AD contamination is proposed. The novelty is represented by a simultaneous determination of 20 ADs with a robust and rapid easy to use wiping and extraction coupled to automatized desorption phase. Therefore sample pretreatment and LC-MS/MS with only 2 columns types and ICP-MS methods resulted very proficient and of high throughput and they make possible a rapid and well defined evaluation of surfaces contamination and personnel exposure in the same time. Other publications in the last years showed similar approaches but they usually lacked in integration of systems, automation of all the analytical phases and high sensibility in terms of LOD and LOQ values, that are essential features when cleaning protocol and decontamination products are still improving. But are designated contamination levels sufficiently rigorous? In this regard, it is plausible to say that international protocols have certainly raised awareness in professionally-exposed staff, as demonstrated by the improvements we observed during this study. A total decontamination of surfaces is very hard to perform, but the strong reduction is indicative of a more efficient cleaning protocol and better products of decontamination. This aspect on surface contamination reduction can also enforce the evaluation about the analytical methods adopted in terms of sensibility and of proficiency. Regarding biological monitoring, however, more work should be done. Few 
analytical methods have been published to measure urinary cytostatic drugs' presence in healthcare workers; furthermore, their very low number of positives demonstrates the need to adopt more sensitive analytical methods. In sum, the environmental and biological monitoring protocol outlined in this work has allowed us to develop optimal procedures for the preparation and administration of ADs.

On a final note, considerable discrepancies in units of measure and sampling procedures across the previous studies were found, which are considered crucial to overcome in future protocols and research. Specifically, the following is proposed:

standardizing reporting units as $\mathrm{pg} / \mathrm{cm}^{2}$ for wipe tests and ng/l for urine,

performing wipe sampling before and after work shifts,

- expressing wipe sampling as median and 90th percentile levels,

applying the standard wipe sampling strategy we have pointed out in this paper,

reporting the drug recovery efficiency of wipe desorption.

\section{REFERENCES}

1. World Health Organization. Global action against cancer [Internet]. Geneva: The Organization; 2003 [cited 2017 Nov 28]. Available from: http://www.who.int/cancer/media/en/788.pdf.

2. Zion Market Research [Internet]. New York: Zion Market Research; 2017-2018 [cited 2017 Nov 28]. Cancer drugs market by therapy (immunotherapy, targeted therapy, chemotherapy, hormone therapy and others) for breast cancer, blood cancer, gastrointestinal cancer, prostate cancer, skin cancer, lung cancer and other cancer: Global industry perspective, comprehensive analysis and forecast, 2015-2021. Available from: https://www.zionmarketresearch.com/news/ global-cancer-drugs-market.

3. Allied Market Research [Internet]. Portland: Allied Market Research; 2018 [cited 2017 Nov 28]. Oncology/Cancer drugs market by therapeutic modalities (chemotherapy, targeted therapy, immunotherapy, hormonal), cancer types (blood, breast, gastrointestinal, prostate, skin, respiratory/ lung cancer) - Global opportunity analysis and industry forecast, 2013-2020. Available from: https://www.alliedmarketresearch.com/oncology-cancer-drugs-market.

4. Il Sole 24 ORE, Sanità24 [Internet]. Turin: Il Sole 24 ORE; 2017 [cited 2017 Nov 28]. Superdrugs: What do their handlers risk? Here comes the Sifo-Aiiao agreement. Available from: http://www.sanita24.ilsole24ore.com/art/lavoro-eprofessione/2017-06-07/superfarmaci-quali-rischi-gli-operatori-che-li-maneggiano-arriva-consensus-sifo-aiiao-172822.php?uuid=AEunFPaB.

5. Lawson CC, Rocheleau CM, Whelan EA, Lividoti Hiber EN, Grajewski B, Spiegelman D, et al. Occupational exposures among nurses and risk of spontaneous abortion. Am J Obstet Gynecol. 2012;206(4):327.e1-8, https://doi. org/10.1016/j.ajog.2011.12.030.

6. Dranitsaris G, Johnston M, Poirier S, Schueller T, Milliken D, Green E, et al. Are health care providers who work with cancer drugs at an increased risk for toxic events? A systematic review and meta-analysis of the literature. J Oncol Pharm Pract. 2005;11:69-78, https://doi.org/10.1191/ 1078155205jp155oa.

7. Mahmoodi M, Soleyman-Jahi S, Zendehdel K, Mozdarani H, Azimi C, Farzanfar F, et al. Chromosomal aberrations, sister chromatid exchanges, and micronuclei in lymphocytes of oncology department personnel handling anti-neoplastic drugs. Drug Chem Toxicol [Internet]. 2017 [cited 2017 Nov 28];40(2):235-40. Available from: https://www.tandfonline.com/doi/abs/10.1080/01480545.2016.1209678?journalCode $=$ idct20.

8. Villarini M, Gianfredi V, Levorato S, Vannini S, Salvatori T, Moretti M. Occupational exposure to cytostatic/antineoplastic drugs and cytogenetic damage measured using the lymphocyte cytokinesis-block micronucleus assay: A systematic review of the literature and meta-analysis. Mutat Res. 2016;770:35-45, https://doi.org/10.1016/j.mrrev.20 16.05.001.

9. Connor TH, MacKenzie BA, DeBord DG, Trout DB, O'Callaghan JP. National Institute for Occupational Safety and Health list of antineoplastic and other hazardous drugs in healthcare settings [Internet]. Cincinnati: Department of Health and Human Services, Centers for Disease Control and Prevention, National Institute for Occupational Safety and Health; 2016 [cited 2017 Nov 28]. Available from: https://www.cdc.gov/niosh/docs/2016-161/pdfs/2016-161. pdf?id=10.26616/NIOSHPUB2016161.

10. Schierl R, Böhlandt A, Nowak D. Guidance values for surface monitoring of antineoplastic drugs in German pharmacies. Ann Occup Hyg. 2009;53(7):703-11, https://doi. org/10.1093/annhyg/mep050.

11. Yoshida J, Koda S, Nishida S, Nakano H, Tei G, Kumagai S. Association between occupational exposure and control measures for antineoplastic drugs in a pharmacy of a hospital. Ann Occup Hyg. 2013;57(2):251-60, https://doi.org/ 10.1093/annhyg/mes061.

12. Silver SR, Steege AL, Boiano JM. Predictors of adherence to safe handling practices for antineoplastic drugs: A survey 
of hospital nurses. J Occup Environ Hyg. 2016;13(3):20312, https://doi.org/10.1080/15459624.2015.1091963.

13. Connor TH, Smith JP. New approaches to wipe sampling methods for antineoplastic and other hazardous drugs in healthcare settings. Pharm Technol Hosp Pharm. 2016; 1(3):107-14, https://doi.org/10.1515/pthp-2016-0009.

14. Kibby T. A review of surface wipe sampling compared to biologic monitoring for occupational exposure to antineoplastic drugs. J Occup Environ Hyg. 2017;14:159-74, https://doi.org/10.1080/15459624.2016.1237026.

15. Polovich M, Clark PC. Factors influencing oncology nurses' use of hazardous drug safe-handling precautions. Oncol Nurs Forum. 2012;39(3):E299-309, https://doi.org/10. 1188/12.ONF.E299-E309.

16. Kupczewska-Dobecka M, Pałaszewska-Tkacz A, Czerczak S, Konieczko K. [Hygiene and legal aspects of occupational exposure assessment to cytostatics]. Med Pr. 2018;69:7792, https://doi.org/10.13075/mp.5893.00599. Polish.

17. American Industrial Hygiene Association. Occupational exposure banding: The solution for the glacial pace of OELs [Internet]. Salt Lake: The Association; 2015 [cited 2018 May 31]. Available from: https://www.aiha.org/publications-and-resources/BoKs/Pages/BoK\%20Resources/Occupational-Exposure-Banding-The-Solution-for-the-Glacial-Pace-of-OELs.aspx.

18. Sessink PJ. Environmental contamination with cytostatic drugs: Past, present and future. Saf Consid Oncol Pharm Special Edition. [Internet]. 2011 [cited 2018 May 31];1-3. Available from: https://pdfs.semanticscholar.org/8652/4d 606dbd8e116ca2c26b1ec70d3f81cfe272.pdf.

19. Kiffmeyer TK, Tuerk J, Hahn M, Stuetzer H, Hadtstein C, Heinemann A, et al. Application and assessment of a regular environmental monitoring of the antineoplastic drug contamination level in pharmacies - The MEWIP project. Ann Occup Hyg. 2013;57(4):444-55, https://doi.org/10. 1093/annhyg/mes081.

20. Böhlandt A, Schierl R. Benefits of wipe sampling: Evaluation of long-term 5-fluorouracil and platinum monitoring data. Pharm Technol Hosp Pharm. 2016;1(3):139-50, https://doi.org/10.1515/pthp-2016-0010.

21. Hedmer M, Wohlfart G. Hygienic guidance values for wipe sampling of antineoplastic drugs in Swedish hospitals. J Environ Monit. 2012;14:1968-75, https://doi.org/10.1039/ c2em10704j.

22. Sottani C, Grignani E, Oddone E, Dezza B, Negri S, Villani S, et al. Monitoring surface contamination by antineoplastic drugs in Italian hospitals: Performance-based hygienic guidance values (HGVs) project. Ann Work Expo Health. 2017;61(8):994-1002, https://doi.org/10.1093/annweh/wxx065.
23. Colombo M, Jeronimo M, Astrakianakis G, Apte C, Hon CY. Wipe sampling method and evaluation of environmental variables for assessing surface contamination of 10 antineoplastic drugs by liquid chromatography/tandem mass spectrometry. Ann Work Expo Health. 2017;61(8):1003-14, https://doi.org/10.1093/annweh/wxx070.

24. Hon CY, Barzan C, Astrakianakis G. Identification of knowledge gaps regarding healthcare workers' exposure to antineoplastic drugs: Review of literature, North America versus Europe. Saf Health Work. 2014;5(4):169-74, https://doi. org/10.1016/j.shaw.2014.06.001.

25. Brouwers EE, Huitema AD, Bakker EN, Douma JW, Schimmel KJ, van Weringh G, et al. Monitoring of platinum surface contamination in seven Dutch hospital pharmacies using inductively coupled plasma mass spectrometry. Int Arch Occup Environ Health. 2007;80(8):689-99, https:// doi.org/10.1007/s00420-007-0181-4.

26. Ndaw S, Denis F, Marsan P, d'Almeida A, Robert A. Biological monitoring of occupational exposure to 5 -fluorouracil: Urinary $\alpha$-fluoro- $\beta$-alanine assay by high performance liquid chromatography tandem mass spectrometry in health care personnel. J Chromatogr B Analyt Technol Biomed Life Sci. 2010;878(27):2630-4, https://doi.org/10.1016/j.jch romb.2010.02.011.

27. Mathias PI, Connor TH, B'Hymer C. A review of high performance liquid chromatographic-mass spectrometric urinary methods for anticancer drug exposure of health care workers. J Chromatogr B Analyt Technol Biomed Life Sci. 2017; 1060:316-24, https://doi.org/10.1016/j.jchromb.2017.06.028.

28. Dugheri S, Bonari S, Pompilio I, Gentili M, Montalti M, Mucci N, et al. A new automated gas chromatography/solid phase microextraction procedure for determining $\alpha$-fluoro- $\beta$-alanine in urine. Malays J Med Sci. 2017;21(5):1091100, https://doi.org/10.17576/mjas-2017-2105-11.

29. Pretty JR, Connor TH, Spasojevic I, Kurtz KS, McLaurin JL, B'Hymer C, et al. Sampling and mass spectrometric analytical methods for five antineoplastic drugs in the healthcare environment. J Oncol Pharm Pract. 2012;18(1):23-36, https://doi.org/10.1177/1078155210389215.

30. Bobin-Dubigeon C, Amiand M, Percheron C, Audeval C, Rochard S, Leynia $\mathrm{P}$, et al. A new, validated wipe-sampling procedure coupled to LC-MS analysis for the simultaneous determination of 5-fluorouracil, doxorubicin and cyclophosphamide in surface contamination. J Anal Toxicol. 2013;37(7):433-9, https://doi.org/10.1093/jat/bkt045.

31. Da Silva CB, Julio IP, Donadel GE, Martins I. UPLC-MS/MS method for simultaneous determination of cyclophosphamide, docetaxel, doxorubicin and 5-fluorouracil in surface samples. J Pharmacol Toxicol Methods. 2016;82:68-73, https://doi.org/10.1016/j.vascn.2016.08.004. 
32. Poupeau C, Tanguay C, Plante C, Gagné S, Caron N, Bussières JF. Pilot study of biological monitoring of four antineoplastic drugs among Canadian healthcare workers. J Oncol Pharm Pract. 2017;23(5):323-32, https://doi.org/ $10.1177 / 1078155216643860$.
33. Rubino FM, Verduci C, Buratti M, Fustinoni S, Campo L, Omodeo-Salè E, et al. Assay of urinary alpha-fluoro-betaalanine by gas chromatography-mass spectrometry for the biological monitoring of occupational exposure to 5-fluorouracil in oncology nurses and pharmacy technicians. Biomed Chromatogr. 2006;20(3):257-66, https://doi.org/ 10.1002/bmc.559.

This work is available in Open Access model and licensed under a Creative Commons Attribution-NonCommercial 3.0 Poland License - http://creativecommons.org/licenses/by-nc/3.0/pl/deed.en. 